\title{
Blood glucose control and microvascular complications - what do we do now?
}

\author{
K. Dahl-Jørgensen ${ }^{1}$, O. Brinchmann-Hansen ${ }^{2}$, H.-J. Bangstad ${ }^{1}$, K. F. Hanssen ${ }^{1}$ \\ ${ }^{1}$ Aker Diabetes Research Centre, Aker University Hospital, Oslo, Norway \\ ${ }^{2}$ Department of Ophthalmology, Ullevål University Hospital, Oslo, Norway
}

Conventional insulin treatment used during the latter part of this century has been unsuccessful in giving most patients with insulin-dependent diabetes mellitus (IDDM) a long normal life. During the last 10 years, however, our knowledge has improved dramatically. We concluded in 1987: "The accumulating evidence for the relationship between blood glucose control and the development and progression of diabetic microangiopathy, and the demonstration that early microangiopathy responds favourably to nearnormoglycaemia, calls for action to improve the care for diabetics. The question regarding blood glucose control is not in essence "why', but 'how'?" [1]. This statement was based on the results from several Scandinavian trials which started $10-12$ years ago [1-7]. Since then further evidence has strengthened the basis of the above conclusion, particularly results from the Stockholm study [8] and the Diabetes Control and Complications Trial (DCCT) [9]. In this review we will summarize the evidence of the benefits of near-normal blood glucose control on the development and progression of late diabetic complications, we will also focus on important areas of future research and how they apply in the clinical environment.

This review was written in connection with the Camillo Golgi lecture given by Kristian F. Hanssen in receipt of the Castello Pedroli Prize at the EASD Annual Meeting in Istanbul, Turkey, September 1993.

Corresponding author: Dr. K. Dahl-Jørgensen, Aker Diabetes Research Centre, Aker University Hospital, N-0514 Oslo, Norway

Abbreviations: CSII, Continuous Subcutaneous insulin infusion; IDDM, insulin-dependent diabetes mellitus; AGE, advanced glycation end products; DCCT, Diabetes Control and Complications Trial

\section{Epidemiological studies}

Even early studies in the 1960's and 1970's suggested an association between poor glycaemic control and increased risk of microvascular complications $[10$, 11]. After the introduction of $\mathrm{HbA}_{1 \mathrm{c}}$ as a reliable measure of long-term blood glucose control, several studies confirmed this association [12-17]. In the Wisconsin study [12], a clear relationship between one single $\mathrm{HbA}_{1 \mathrm{c}}$ measurement and the progression of retinopathy during the following 10 years was demonstrated. A population-based study in Norway demonstrated a dose-response relationship between $\mathrm{HbA}_{1 \mathrm{c}}$ and prevalence of both retinopathy and microalbuminuria in young IDDM patients [18].

These data demonstrate an association between glycaemic control and risk of late complications, and a lower incidence of complications in "well-controlled" patients. However, only prospective randomized trials will be able to answer the question of whether the association between good metabolic control and fewer complications is due to the effective treatment or to the "mildness" of the disease [19].

\section{Intervention trials}

Secondary prevention of late complications: Home blood glucose monitoring created a practical basis for introducing intensified insulin regimens aiming at near-normal blood glucose levels: i. e., continuous subcutaneous insulin infusion (CSII) by portable pumps and multiple insulin injection regimens by use of insulin "pens". In the long term glycaemic control was monitored by $\mathrm{HbA}_{1 \mathrm{c}}$ measurements. This made it possible to test the hypothesis that nearnormoglycaemia retarded the progression of late complications and led to several trials in the early 


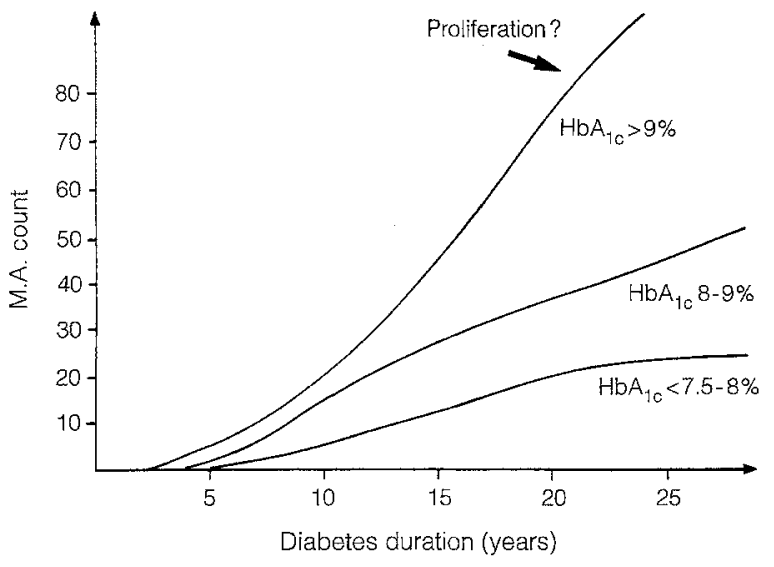

Fig. 1. A hypothetical model of the developiment of microaneurysms and haemorrhages (M. A. counts) with diabetes duration and level of $\mathrm{HbA}_{1 \mathrm{c}}$, based on data from the Oslo study

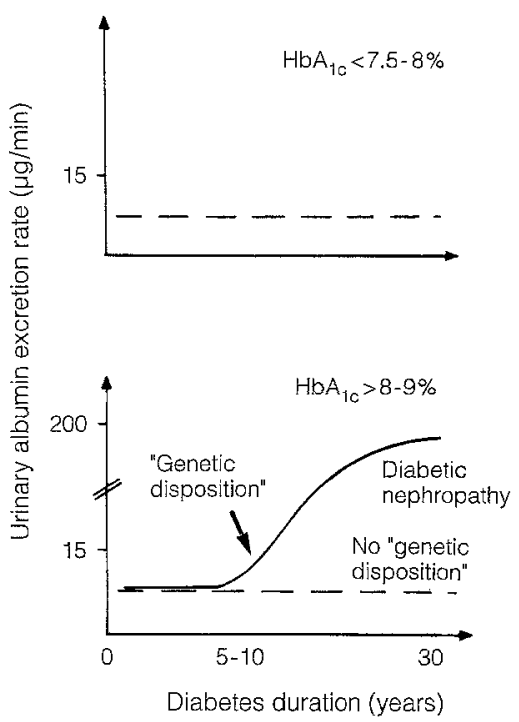

Fig. 2. A hypothetical model of the development and progression of urinary albumin excretion in IDDM patients, based on data from the Oslo study

1980's [2-5, 20-23] which aimed at secondary prevention, as the study populations already had variable degrees of complications.

In the Oslo study [1] 45 IDDM patients aged 1842 years had been followed-up since 1982 . During the first 4 years the patients were randomized to either CSII, multiple injections or two daily injections. After 2 years, less progression of retinopathy and neuropathy was reported on CSII [5]. During the first 6 months a transient deterioration of retinopathy with development of soft exudates due to rapid lowering of blood glucose was reported [21, 24], which was observed in most trials $[1,2,9,20]$. Due to favourable results for intensified treatment, the patients on two injections were offered intensified treatment after 4 years, and were followed-up according to $\mathrm{HbA}_{1 \mathrm{c}}$ levels thereafter. After 7 years the patients developing soft exudates in the retina, and having the best long-term glycaemic control, had less retinopathy [25]. After 7 years patients with $\mathrm{HbA}_{1 \mathrm{c}}$ levels of less than $8 \%$ had significantly less retinopathy than those with $\mathrm{HbA}_{1 \mathrm{c}}$ above this level (Fig.1). During the first 4 years CSII patients had significantly reduced urinary albumin excretion compared to control subjects [26]. After 7 years, 8 of 10 patients with $\mathrm{HbA}_{1 \mathrm{c}}$ levels less than $7 \%$ had reduced their urinary albumin excretion, while 4 of 8 patients with $\mathrm{HbA}_{1 \mathrm{c}}$ levels of greater than $9 \%$ increased to more than $200 \mathrm{mg} / 24 \mathrm{~h}$ [27] (Fig. 2). Nerve conduction velocities improved on CSII compared to control subjects during the first 2 years [1], and after 8 years less deterioration was found in the patients with well-controlled diabetes [28].

In the Steno II study [3] 36 patients with microalbuminuria were randomized to CSII or conventional treatment. After 2 years the progression in fractional albumin clearance was prevented in the CSII patients but not in the control subjects. When combining the Steno I and II studies, a significantly greater number of control patients with microalbuminuria developed clinical nephropathy and arterial hypertension than patients on CSII [29].

The Stockholm study [8] randomized 102 patients to either multiple injection treatment or standard treatment (two daily injections). This trial convincingly demonstrated less progression on intensified treatment after 7 years regarding all measures of microangiopathy. Laser treatment was required by $27 \%$ of the patients who developed severe retinopathy in the intensified treatment group, vs $52 \%$ on standard treatment. Nephropathy developed in one patient on intensified treatment vs nine patients on standard treatment. The nerve conduction velocities progress significantly more in the standardtreatment group than in the intensified treatment group.

In a meta-analysis of 16 randomized trials of intensified therapy (including the studies already mentioned) it was concluded that long-term intensive blood glucose control significantly reduces the risk of the progression of retinopathy (odds ratio 0.49 ) and nephropathy (odds ratio 0.34) [30].

In Scandinavia these results have led to an improvement in the quality of IDDM treatment in the last $5-7$ years. Nearly all patients may choose intensified insulin treatment if they wish, and at present in most clinics $50-80 \%$ of the patients use multiple insulin injections.

Primary prevention of late complications: The only study addressing prevention of complications in newly-diagnosed IDDM patients, has been the Diabetes Control and Complications Trial (DCCT) [9] in which 726 patients with no retinopathy (primary prevention cohort) and 715 patients with mild retinopathy (secondary intervention cohort) were random- 
ized to either intensified insulin treatment (CSII and/ or multiple injections) or regular treatment (one or two injections daily) and followed for 3-9 years (mean 6.5 years). It is impressive that $99 \%$ of the patients completed this large trial. The study was completed 1 year before schedule due to conclusive results demonstrating the benefit of intensified treatment in preventing the development and progression of complications.

In the primary prevention cohort, intensive treatment reduced the risk of developing retinopathy by $76 \%$ as compared to conventional treatment. In the patients who already had some retinopathy, intensified treatment slowed the progression by $54 \%$, and reduced the development of proliferative or severe non-proliferative retinopathy by $47 \%$. In the combined cohorts, intensive treatment reduced the occurrence of microalbuminuria (urinary albumin excretion $>40 \mathrm{mg} / 24 \mathrm{~h}$ ) by $39 \%$, that of albuminuria (>300 mg/24 h) by $54 \%$ and that of clinical neuropathy by $60 \%$. The mean difference in $\mathrm{HbA}_{1 \mathrm{c}}$ between intensified and regular treatment was $1.5-1.7 \%$ throughout the study, similar to the other studies cited.

After the DCCT no doubt exists that intensified insulin treatment achieving near-normal blood glucose levels reduces the risk of microangiopathy.

Morphology studies: The clinical trials cited above have mainly used functional parameters as endpoints of complications. Only for retinopathy has morphology been extensively used when counting microaneurysms and assessing proliferations. Few studies have addressed the question of whether other morphological changes were favourably influenced by strict glycaemic control. Bangstad et al. [31] recently reported a trial using morphometric data from kidney biopsies as endpoints: 18 young IDDM patients with microalbuminuria were randomized to CSII or regular treatment (3-5 daily insulin injections) achieving a difference of $1.2 \%$. $\mathrm{HbA}_{1 \mathrm{c}}$ during a $24-36$ month period. In the CSII group glomerular basement membrane thickness increased to $56 \mathrm{~nm}$ vs $140 \mathrm{~nm}$ in the conventional group. Also a significant difference in matrix/mesangial volume fraction was observed. The increase in these parameters correlated to the mean $\mathrm{HbA}_{1 \mathrm{c}}$ throughout the study.

The biochemical mechanism of microvascular complications: The initiation and progression of microvascular complications has been shown to be closely linked to the level of glycated haemoglobin. This may indicate that glycated haemoglobin is not only a marker of mean blood glucose, but that mechanisms connected to glycation itself are important for the development of microvascular complications.

The amadori products formed by glycation of proteins undergo a series of complex reactions to form advanced glycation endproducts (AGE) [32]. There are many pathological consequences of AGE formation that may explain features of pathogenesis of diabetic microvascular complications:

- AGE formation interferes with basement membrane self-assembly which may lead to increased capillary permeability.

- AGE formation decreases binding affinity for growth-modulating heparan sulphate proteoglycan which may lead to increased permeability in the glomerulus and hence to microalbuminuria.

- AGE formation reduces susceptibility to enzymatic degradation and leads to accumulation of AGE in vessel walls.

It is also interesting that an inhibitor of AGE formation, aminoguanidine, has been shown to inhibit the development of diabetic retinopathy, neuropathy and nephropathy in experimental animals. It remains to be seen whether this drug is safe and effective in the human diabetic patient.

We have identified increased AGE albumin levels in IDDM subjects compared to normal control subjects in preliminary experiments using an immunoassay with antibodies directed towards AGE products.

\section{Do the findings in IDDM also apply to NIDDM?}

There should now be no doubt that hyperglycaemia is the main factor in the development and progression of microvascular complications in IDDM. Epidemiological evidence also points to a strong association between $\mathrm{HbA}_{1 \mathrm{c}}$ and microvascular lesions in NIDDM. In the Wisconsin study [12] a four-fold risk of progression of retinopathy in the cohort of NIDDM patients who consistently had $\mathrm{HbA}_{1 \mathrm{c}}$ levels above the median of the total cohort studied was demonstrated. These results were parallel to the results in the IDDM groups. The ongoing prospective NIDDM trials will hopefully answer this question [33].

NIDDM patients should meanwhile be offered appropriate treatment (diet, exercise, oral antidiabetic therapy or insulin) aiming at near-normoglycaemia. However, individual targets for glycaemic control are especially necessary in this group, taking into consideration weight gain and risk of hypoglycaemia with insulin treatment in elderly subjects.

The major cause of death in diabetic patients is macrovascular, and not microvascular, disease. A key question regarding the life prognosis of diabetic patients is therefore whether intensive insulin treatment also reduces macrovascular disease. The results from the DCCT are interesting: when all major cardiovascular and peripheral vascular events were combined, intensive therapy reduced somewhat the risk of macrovascular disease by $41 \%$. It is important to stress that these patients were young (13 to 39 years of age) and that treatment-related differences in 


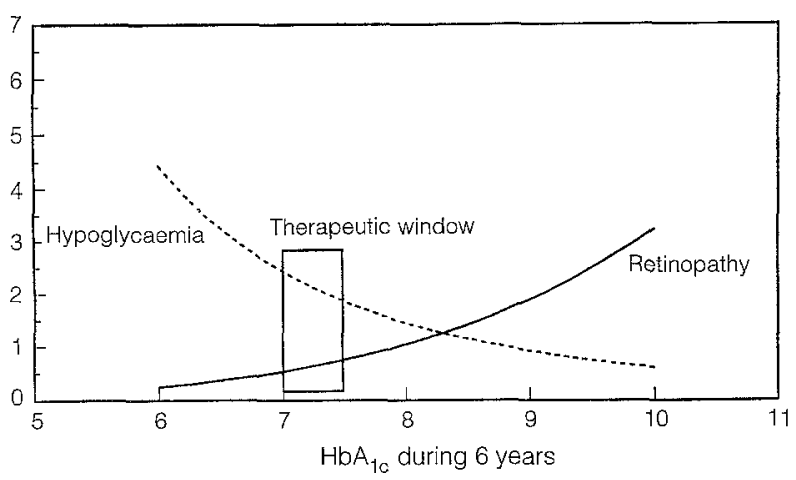

Fig.3. A graphic presentation of the relative risk of retinopathy and hypoglycaemia based on data from various studies. A therapeutic window is indicated. The graph is only a visual presentation of data and does not intend to be an exact description of the relationship in the individual patient

rates of macrovascular events were unlikely to be detected. A greater effect might be detected in an older age group with a higher natural incidence of macrovascular events. Intensive treatment reduced the development of hypercholesterolaemia by $34 \%$. This indicates major benefits of intensive treatment regarding life expectancy.

\section{What should be the goal for glycaemic control?}

Any permanent reduction in $\mathrm{HbA}_{1 \mathrm{c}}$ reduces the risk of complications. Retinopathy progression in the DCCT was perhaps curvilinear related to $\mathrm{HbA}_{1 \mathrm{c}}$ [9]. The DCCT data indicate that $\mathrm{HbA}_{1 \mathrm{c}}$ within the 95th percentile (2 SD above mean) of non-diabetic subjects may be needed to avoid the development of any microvascular complications. That is $\mathrm{HbA}_{1 \mathrm{c}}$ of approximately $6 \%$ measured with most methods. However, large differences may exist between different methods of $\mathrm{HbA}_{1 \mathrm{c}}$ analysis, and it is mandatory to compare with appropriate reference values. To avoid serious complications several intervention trials indicate that $\mathrm{HbA}_{1 \mathrm{c}}$ levels less than $7.5 \%$ may be sufficient in most cases (upper normal reference value $<6 \%$ ). Goldstein et al. [34] reported that all patients developing retinopathy requiring laser treatment had $\mathrm{HbA}_{1 \mathrm{c}}$ levels greater than $8.5 \%$ during the preceding 14 years. In the Stockholm study all patients who developed clinical nephropathy had $\mathrm{HbA}_{1 \mathrm{c}}$ levels greater than $8.5 \%$. This may indicate that a long-term $\mathrm{HbA}_{1 \mathrm{c}}$ level of about $+4 \mathrm{SD}$ above the mean for non-diabetic subjects may be sufficient to avoid serious complications in most patients, although below +2 SD may be necessary to completely avoid development of complications. These goals are realistic with regard to the risk of hypoglycaemia. The level of $7-8 \%$ may be the cross of the curve of the relation between $\mathrm{HbA}_{1 \mathrm{c}}$ and progression of retinopathy, and the curve of risk of hypo- glycaemia and $\mathrm{HbA}_{1 \mathrm{c}}$ levels (Fig. 3). We may postulate a "therapeutic window" of $\mathrm{HbA}_{1 \mathrm{c}}$ as a recommended target for glycaemic control.

\section{What are the negative consequences of achieving near-normoglycaemia}

With the present insulin treatment, the answer is more frequent and more severe hypoglycaemia. In the DCCT the risk of severe hypoglycaemia increased two- to threefold on intensive treatment compared to conventional treatment [9]. However, the control group had high $\mathrm{HbA}_{1 \mathrm{c}}$ and low incidence of hypoglycaemia. When trying to improve blood glucose with two daily injections of mixed NPH/rapid insulin in the initial phase of the Oslo study [1] the risk of severe hypoglycaemia increased dramatically. The Oslo study also concluded that it was more dangerous to reduce the mean blood glucose levels into the near-normal range by means of multiple injection treatment than with insulin pump treatment [1]. This may be due to fewer blood glucose excursions on CSII than on multiple injection treatment. More comparative studies are needed to confirm this.

In patients with hypoglycaemia unawareness, special care is needed when intensive therapy is introduced. These patients with longstanding diabetes have diminished adrenergic symptoms of hypoglycaemia and reduced hormonal counterregulation [35]. Intensive treatment may further diminish the warning symptoms of hypoglycaemia, but may also induce this condition in patients who previously had normal symptoms of hypoglycaemia. Hypoglycaemia unawareness may be reversed by increasing mean blood glucose levels and avoiding hypoglycaemia for several weeks [36]. In such cases more frequent home blood glucose measurements are necessary. Insulin pump treatment does reduce the blood glucose excursions, but the goal of glycaemic control should be higher than the goals recommended above $\left(\mathrm{HbA}_{1 \mathrm{c}} \sim 8-8.5 \%\right.$ instead of 7-7.5\%).

It may also be necessary to have a higher target $\mathrm{HbA}_{1 \mathrm{c}}$ in children than in adults. Hypoglycaemia should be avoided if possible to avoid affecting the developing brain. To reduce the risk of hypoglycaemia a goal of $\mathrm{HbA}_{1 \mathrm{c}}$ of approximately $8-8.5 \%$ (4 SD above the mean of non-diabetic subjects) may be realistic. However, intensified treatment by means of multiple injections may be used also in young children. Indwelling subcutaneous catheters can reduce the pain and discomfort associated with frequent injections. Insulin pumps may be well-tolerated after about 12 years of age, but have been used in younger children for shorter periods $[37,38]$. 


\section{How do we implement these goals into clinical practice?}

For many patients the present insulin regimen creates problems in their daily life. Many patients feel there is an imbalance between the energy and self discipline they have to invest and the outcome, with regard to blood glucose stability. There may be a conflict of interest between the demands of the health care professionals and the patients' feelings and needs. Many patients feel that achieving good blood glucose levels is too high a price to pay to lose a good quality of life which is more important than a long life to most patients. This conflict of interest may create psychosocial problems that may interfere with treatment. By introducing intensive treatment the patients' personal demands must be met: treatment must be "tailormade" with all aspects of daily life being taken into consideration. Patients undergoing intensive treatment by means of 4- 6 daily insulin injections (before meals) should be taught how to adjust insulin dose according to size, composition and timing of the meal (and extra snacks), to planned exercise and to actual blood glucose value. This may take time, and systematic training is necessary. (For instance, the adolescent patient should learn how much insulin is needed to eat a chocolate). The benefit to the patient is freedom to live independently and maintain good blood glucose control which should be the main goal. However, in order to maintain the patients' motivation and enthusiasm, it is necessary to set individual short-term targets. The feeling of being able to handle these challenges oneby-one in their own time may reduce the psychological problems. Our experience is that many patients still give priority to "the good life" over optimal blood glucose control when intensified treatment is introduced. Further psychological and pedagogic research is needed to develop age-specific strategies for this work.

In order to achieve these goals of treatment more specially-trained diabetes nurses are needed to motivate and educate the patients. Patients with long experience in intensified treatment may also be used in the education of other patients.

More money to supply home blood glucose monitoring systems, insulin pens and insulin pumps is necessary. These are unobtainable in many parts of the world at the present time. For the politicians we have to document, with cost-benefit analysis, that intensified treatment is cost effective in a short period of time. The social and private insurance systems will then hopefully give priority to financing intensive treatment.

Where to start? We should train/ more diabetes nurses. We should use the diabetic patients' own resources more fully by planning care together with the diabetes associations, and perhaps use the pa- tients as educators. We should not make intensified treatment more difficult than necessary. We should concentrate on the patients with badly-controlled diabetes. We may then see no more severe diabetic complications by the year 2005 !

Acknowledgements. First, thanks to our patients willing to take part in our clinical research for so many years. We would like to thank our colleagues and collaborators at Aker University Hospital and the cooperating institutions: the National Hospital, Ullevål University Hospital, Medstat Statistical Institute, Århus University and Steno Diabetes Centre. The authors have been supported by grants from The Norwegian Research Council, Norwegian Diabetes Association, Isbergs Foundation, Jahre's Research Foundation, Lions International, Novo Nordisk Pharma Ltd., The University of Oslo and Aker Diabetes Research Foundation.

\section{References}

1. Dahl-Jørgensen K (1987) Near-normoglycemia and late diabetic complications. The Oslo Study (Thesis). Acta Endocrinol (Copenh) 115 [Suppl 284]: 1-56

2. Lauritzen T, Frost-Larsen K, Larsen HW, Deckert T and the Steno Study group (1985) Two year experience with continuous subcutaneous insulin infusion in relation to retinopathy and neuropathy. Diabetes 35 [Suppl 3]: 74-79

3. Feldt-Rasmussen B, Mathiesen ER, Deckert T (1986) Effect of 2 years of strict metabolic control on progression of incipient nephropathy in insulin-dependent diabetes. Lancet I: $1300-1304$

4. Beck-Nielsen H, Richelsen B, Mogensen CE, Olsen T, Ehlers N, Nielsen CB et al. (1985) Effect of insulin pump treatment for 1 year on renal function and retinal morphology in patients with IDDM. Diabetes Care 8: 585-589

5. Dahl-Jørgensen K, Brinchmann-Hansen O, Hanssen KF, Ganes T, Kierulf P, Smeland E et al. (1986) Effect of nearnormoglycaemia for two years on progression of early diabetic retinopathy, nephropathy and neuropathy, the Oslo Study. BMJ 293: 1195-1199

6. Hanssen KF, Bangstad H-J, Brinchmann-Hansen O, DahlJørgensen K (1992) Blood glucose control and diabetic microvascular complications - long term effects of near-normoglycemia. Diabet Med 9: 697-705

7. Hanssen KF, Dahl-Jørgensen K, Lauritzen T, Feldt-Rasmussen B, Brinchmann-Hansen O, Deckert T (1986) Diabetic control and microvascular complications - the nearnormoglycemic experience. Diabetologia 29: 677-684

8. Reichard P, Nilsson B-Y, Rosenqvist U (1993) The effect of long-term intensified insulin treatment on the development of microvascular complications of diabetes mellitus. N Engl J Med 329: 304-309

9. The Diabetes Control and Complications Trial Research Group (1993) The effect of intensive treatment of diabetes on the development and progression of long-term complications in insulin-dependent diabetes mellitus. $\mathrm{N}$ Engl J Med 329: 977-986

10. Johnsson S (1960) Retinopathy and nephropathy in diabetes mellitus: comparison of the effects of two forms of treatment. Diabetes 9:1-8

11. Pirart T (1978) Diabetes mellitus and its degenerative complications: a prospective study of 4400 patients observed between 1947 and 1973. Diabetes Care 1:168-188

12. Klein R, Klein BEK, Moss SE, Cruickshanks KJ (1993) Glycosylated hemoglobin predicts the 10 -year progression 
of diabetic retinopathy. Diabetes 42 [Suppl 1] 29A (Abstract)

13. Doft BH, Kingsley LA, Orchard TF, Kuller L, Drash A, Becker D (1984) The association between long-term diabetic control and early retinopathy. Ophthalmology 91: 763-769

14. Weber B, Burger W, Hartmann R, Hövener G, Malchus R, Oberdisse U (1986) Risk factors for the development of retinopathy in children and adolescents with type 1 (insulindependent) diabetes mellitus. Diabetologia 29:23-29

15. Wiseman M, Viberti GC, Mackintosh D, Jarrett RF, Keen H (1984) Glycaemia, arterial pressure and microalbuminuria in type 1 (insulin-dependent) diabetes mellitus. Diabetologia 26: 401-405

16. Bangstad H-J, Hanssen KF, Dahl-Jørgensen K, Aagenæs $\varnothing$ (1989) Microalbuminuria is associated with long term poor glycemic control in adolescent insulin dependent diabetics. Diabetes Res 12: 71-74

17. Mortensen HB, Martinelli K, Nørgaard K, Main K, Kastrup KW, Ibsen KK et al. (1990) A nation-wide cross-sectional study of urinary albumin excretion rate, arterial blood pressure and blood glucose control in Danish children with type 1 diabetes mellitus. Diabet Med 7: 887-897

18. Joner G, Brinchmann-Hansen O, Torres CG, Hanssen KF (1992) A nationwide cross-sectional study of retinopathy and microalbuminuria in young Norwegian type 1 (insulin-dependent) diabetic patients. Diabetologia 35: 10491054

19. Keen H (1984) Normoglycemia re-entry and diabetic complications. Diabet Med 1: 85-87

20. KROC Collaborative Study Group (1988) Diabetic retinopathy after two years of intensified insulin treatment. JAMA 260: 37-41

21. Dahl-Jørgensen K, Brinchmann-Hansen O, Hanssen KF, Sandvik L, Aagenæs $\varnothing$ (1985) Rapid tightening of blood glucose control leads to transient deterioration of retinopathy in insulin dependent diabetes mellitus. The Oslo Study. BMJ 290: 811-815

22. CNR Study Group on Diabetic Retinopathy (1989) The effect of continuous insulin infusion as compared with conventional insulin therapy in the evolution of diabetic retinal ischemia - two years report. Diab Nutri Metab 3: 165174

23. Reichard P, Berglund B, Britz A, Cars I, Nilsson BT, Rosenqvist U (1991) Intensified conventional insulin treatment retards the microvascular complications of insulin dependent diabetes mellitus (IDDM): The Stockholm Diabetes Intervention Study after five years. J Int Med 230: 101-108

24. Rosenlund E, Haakens K, Brinchmann-Hansen O, DahlJ $\varnothing$ rgensen K, Hanssen KF (1988) Transient proliferative retinopathy during intensified insulin treatment. Am $J$ Ophthalmol 105: 618-625
25. Brinchmann-Hansen O, Dahl-Jørgensen K, Sandvik L, Hanssen KF (1992) Blood glucose concentrations and progression of diabetic retinopathy: the seven year results of the Oslo Study. BMJ 304: 19-22

26. Dahl-Jørgensen K, Hanssen KF, Kierulf P, Bjøro T, Sandvik L, Aagenæs $\emptyset$ (1988) Reduction of urinary albumin excretion after 4 years of continuous subcutaneous insulin infusion in insulin-dependent diabetes mellitus. Acta Endocrinol (Copenh) 117: 19-25

27. Dahl-Jørgensen K, Bjøro T, Kierulf P, Sandvik L, Bangstad H-J, Hanssen KF (1992) Long term glycemic control and kidney function in insulin-dependent diabetes mellitus. Kidney Int 41: 920-923

28. Amthor KF, Dahl-Jørgensen K, Berg TJ, Hanssen KF, Skard Heier M, Sandvik L, Aagenæs Ø (1994) The effect of eight years of strict glycaemic control on peripheral nerve function in insulin-dependent diabetes mellitus. The Oslo Study. Diabetologia 37: 579-584

29. Feldt-Rasmussen B, Mathiesen ER, Jensen T, Lauritzen T, Deckert T (1991) Effect of improved metabolic control on loss of kidney function in insulin-dependent diabetic patients. Diabetologia 34: 164-170

30. Wang PH, Lau J, Chalmers TC (1993) Meta-analysis of effects of intensive blood-glucose control on late complications of type-1 diabetes. Lancet 341: 1306-1309

31. Bangstad H-J, Dahl-Jørgensen K, Hartmann A, Hanssen KF (1994) Improvement of blood glucose control retards the progression of morphological changes in early diabetic nephropathy. Diabetologia 37: 483-490

32. Bucala R, Cerami A (1992) Advanced glycosylation: chemistry, biology, and implications for diabetes and aging. Adv Pharmacol 23: 1-34

33. UK Prospective Diabetes Study Group (1991) UK Prospective Diabetes Study VIII: study design, progress and performance. Diabetologia 34: 877-890

34. Goldstein DE, Blinder KJ, Ide CH et al. (1993) Glycemic control and development of retinopathy in youth-onset insulin-dependent diabetes mellitus. Ophthalmology 10;30: $1-8$

35. Bolli G, De Feo P, Compagnucci P et al. (1983) Abnormal glucose counterregulation in insulin-dependent diabetes mellitus: interaction of anti-insulin antibodies and impaired glucagon and epinephrine secretion. Diabetes 32: 134-141

36. Bolli GB, Fanelli C, Epifano L et al. (1993) Reversibility of hypoglycaemia unawareness in type 1 diabetes mellitus: the one year report. Diabetologia 36 [Suppl 1]: A37 (Abstract)

37. Beaufort CE de, Bruining GJ (1987) Continuous subcutaneous insulin infusion in children. Diabet Med 4: 103-108

38. Brink SJ, Stewart C (1986) Insulin pump treatment in insulin-dependent diabetes mellitus. JAMA 5; 225: 617-621 